\title{
Geogebra untuk Pembelajaran Vektor
}

\author{
Rarri Bian Ryandi ${ }^{1, *}$, Diah Dwi Santri ${ }^{2}$ \\ ${ }^{1}$ Universitas Adiwangsa Jambi \\ ${ }^{2}$ STIT Mamba'ul Ulum Jambi \\ * rarri.bianryandi@gmail.com
}

\begin{tabular}{|l|l|l|l|} 
Received: 09-10-2020 & Revised: 01-05-2021 & Accepted: 23-05-2021 & Published: 06-06-2021 \\
\hline
\end{tabular}

\begin{abstract}
ABSTRAK
Berdasarkan hasil observasi didapatkan fakta banyak peserta didik yang kesulitan dalam memahami pelajaran matematika, hal ini disebabkan kurangnya pemahaman materi, serta kurangnya minat dalam mengikuti pembelajaran matematika. Penelitian ini menghasilkan sebuah lintasan belajar menggunakan geogebra untuk membantu memahami konsep vektor. Metode penelitian yang digunakan adalah design research yang dapat mengembangkan teori pembelajaran lokal. Lintasan belajar pada tahap awal dan dicoba pada 28 peserta didik SMK Baiturrahim Jambi. Hasil penelitian yang ingin dicapai pada lintasan pembelajaran ini terdiri dari 3 aktivitas: 1) Siswa mengilustrasikan rute perjalanan dan menjelaskan cara menentukan jarak dari suatu tempat ketempat lain. 2) Siswa mengubah dua titik yang berhubungan menjadi vektor dan menggambarkannya kedalam koordinat kartesius, memahami definisi vektor menggunakan pengetahuan dan bahasa sendiri dan memahami pengurangan dan penjumlahan vektor menggunakan geogebra. 3) Siswa menyelesaikan permasalahan pengurangan dan penjumlahan vektor dalam bentuk rumit. Dari aktivitas yang dihasilkan dan diujicobakan pada pembelajaran Vektor menggunakan Software Geogebra dapat membantu siswa memahami konsep Vektor secara lebih terstruktur dengan asumsi dan model yang dirancang sendiri sehingga berkembang ke matematika yang lebih formal.
\end{abstract}

Kata Kunci : Design Research, Vektor, Geogebra

\begin{abstract}
Based on the results of observations, it is found that many students have difficulty understanding mathematics, this is due to understanding the material, as well as a lack of interest in participating in mathematics learning. The study produced a learning trajectories using geogebra that can help students understand the concept of a vector. This study used research design as the research methodology to develop classroom learning theory in learning a vector. This trajectories learning is designed at an earlier stage and been tested by the 28 students in SMK Baiturrahim Jambi.The result of this study is trajectories learning consisting of 3 activities : 1) Students illustrate routes and explain how to ascertain the distance from one place to another, 2)Students change two point which associated each other to be vector and describe it into kartesius coordinate, understand the vector definition using their own words and understand the addition and substraction of the vector using geogebra. 3) Students solve the problem related to the addition and substraction of the vector into the more complicated form. From the generated and tried out activities, it can be concluded that using Geogebra can help the students in understanding the concept of the vector structurally using assumption and models they designed by themselves so it developed gradually to the mathematics formal.
\end{abstract}

Keywords: Design Research, Vector, Geogebra 


\section{PENDAHULUAN}

Matematika merupakan pembelajaran yang tidak lepas dari kehidupan manusia. Karena pentingnya pembelajaran matematika, maka pembelajaran matematika ada disetiap jenjang pendidikan di Indonesia (Maskur et al., 2020). Matematika merupakan pembelajaran yang memberikan "ketakutan" terhadap peserta didik. Sehingga, matematika mempunyai peminat paling sedikit jika dilihat dari pelajaran lain (Putra \& Anggraini, 2016). Oleh sebab itu, agar peserta didik tidak merasa takut dan kesulitan maka pembelajaran matematika harus dibuat semenarik mungkin. Menurut Murizal, Yarman, \& Yerizon (2012) dalam pembelajaran matematika peserta didik diharapkan bisa memahami konsep terlebih dahulu serta mampu menyelesaikan soal-soal dan dapat mengaplikasi pembelajaran pada dunia nyata.

Guru sebagai pelaksana dalam mewujudkan cita-cita nasional harus melaksanakan tugasnya dengan mencocokkan dan menggunakan strategi yang dapat melibatkan keaktifan siswa pada saat proses pembelajaran sehingga siswa mampu berpikir kreatif, mampu mengamati, mencoba, berani mengungkapkan jawaban dan pendapatnya (Suherman, dkk., 2003) dan melaksanakan inovasi-inovasi dalam proses pembelajaran (Wijayanti \& Sungkono, 2017), agar dapat memberikan kesempatan kepada siswa untuk lebih aktif dan dominan pada proses pembelajaran (Ari Septian, 2017; Ari Septian, Sugiarni, \& Monariska, 2020).

Berdasarkan hasil observasi peneliti di kelas XI SMK Baiturrahim didapatkan fakta bahwa banyak peserta didik yang kesulitan dalam memahami pelajaran matematika. Hal ini dapat mengakibatkan kurangnya pemahaman materi, serta kurangnya minat dalam mengikuti pembelajaran matematika dan banyak ditemukan peserta didik yang berbicara serta bermain pada saat aktivitas pembelajaran di laksanakan. Salah satu materi matematika yang ada pada sekolah tingkat SMK kelas XI adalah vektor, kesulitan peserta didik dalam memahami materi vektor adalah 1) Pembelajaran vektor masih bersifat informatif; 2) Konsep materi vektor yang diajarkan dalam pembelajaran bersifat abstrak; 3) Pada pembelajaran vektor, guru tidak mengaitkan dengan kehidupan sehari-hari (Suwarto \& Purnami, 2018). Hal ini mengakibatkan hasil pembelajaran peserta didik masih di bawah rata-rata. Untuk meningkatkan dan membantu siswa memahami serta mengkonkretkan materi yang abstrak diperlukan suatu media pembelajaran.

Media yang dapat diaplikasikan dalam penelitian ini adalah Software GeoGebra. Software Geogebra ini memiliki fungsi sebagai media pembelajaran yang dinamis, karena siswa bisa bermain dengan menggunakan titik-titik maupun grafik-grafik yang dapat 
menarik minat dan kreatifitas siswa dalam belajar matematika (Kurniawati, 2018; A Septian, Darhim, \& Prabawanto, 2020). Dengan menggunakan Software Geogebra siswa dapat merasakan pengalaman langsung dari pembelajaran (Orozco \& Morales-Morgado, 2017). Dengan demikian, Software GeoGebra mendukung kreatifitas siswa dan memotivasi siswa dalam belajar Geogebra (Budiman \& Rosmiati, 2020; Suryawan \& Permana, 2020).

Penelitian terdahulu yang menggunakan geogebra dalam pembelajaran juga telah mendapatkan hasil yang maksimal antara lain penelitian Japa, Suarjana, \& Widiana (2017) menyatakan pembelajaran menggunakan media geogebra dapat meningkatkan kemampuan spasial siswa. Penggunaan Geogebra dapat meningkatan kemampuan memecahkan masalah matematis (Septian, 2017). Pembelajaran menggunakan GeoGebra lebih baik daripada pembelajaran menggunakan ekspositori Sedangkan berdasarkan hasil penelitian Suryawan \& Permana (2020) didapatkan bahwa pemahaman konsep matematika siswa meningkatkan dengan menggunakan Geogebra. Dari hasil penelitian yang menggunakan Geogebra dapat dijadikan patokan dalam aktivasi sumber belajar matematika yang sesuai pada era revolusi industri 4.0.

Berdasarkan dari penelitian tersebut, peneliti tertarik merancang pembelajaran vektor menggunakan geogebra dengan menggunakan konteks yang dialami siswa dalam kehidupan sehari-hari yaitu rute perjalanan siswa dari rumah menuju sekolah agar lebih menarik perhatian siswa dalam memahami konsep vektor, dari pembelajaran ini siswa dapat meningkatkan kreativitasnya dan meningkatkan kemampuan matematis dengan menggambar rute perjalanannya dan menghitung jarak yang dia tempuh dengan menggunakan aplikasi Geogebra. Rute perjalanan yang di gambarkan siswa membuat pembelajaran materi vektor lebih terlihat menarik bagi siswa dan penggabunggan dengan aplikasi Geogebra dalam mempelajari vektor membuat penelitian ini berbeda dari penelitian sebelumnya.

Berdasarkan pembahasan tersebut, peneliti bertujuan untuk membantu siswa memahami konsep vektor dengan mengembangkan sebuah lintasan belajar menggunakan rute perjalanan siswa dari rumah menuju sekolah dan menyelesaikan permasalahan vektor menggunakan aplikasi Geogebra .

\section{METODE PENELITIAN}

Metode penelitian yang digunakan peneliti ada metode design research. Design research digunakan dalam mengembangkan local instructional theory yang didasarkan 
pada teori (theory-driven) dan percobaan secara empiris (empiricly based) melalui kerja sama diantara guru dan peneliti dalam meningkatkan kesinambungan antara kebijakan dan proses pembelajaran disekolah (Gravemeijer \& Eerde, 2009). Tahapan Design Research tergambar pada tiga tahapan yang terlihat pada bagan dibawah (Gravemeijer, 2004).

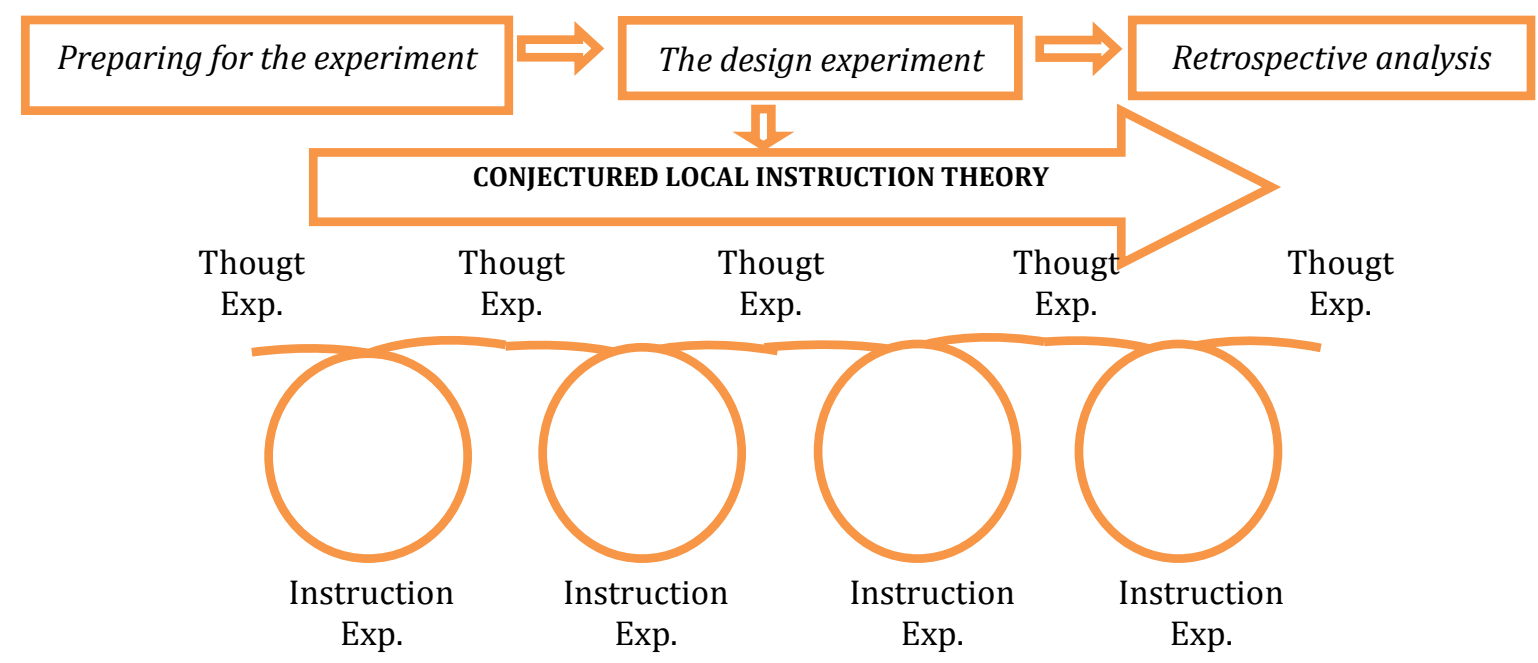

Gambar 1. Siklik Design Research (Gravemeijer, 2004)

Tahap persiapan (preliminary design stage) meliputi pengkajian literatur, diskusi bersama guru model dan merancang Learning Instructional Trajectory (LIT) dengan instrumen Hypotheticall Learning Trajectory (HLT); (2) tahap ujicoba pembelajaran meliputi piloting experiment dan teaching experiment dengan subyek 28 orang siswa SMK Baiturrahim, Kabupaten Ogan Ilir dan (3) tahap analisis retrospektif (retrospective analysis), yaitu analisis yang membandingkan HLT dengan lintasan belajar siswa yang sebenarnya sehingga diperoleh jawaban atas pertanyaan penelitian.

Data penelitian ini dikumpulkan melalui tes, pengamatan, wawancara, dan dokumentasi berupa hasil aktivitas belajar, hasil belajar siswa, foto dan rekaman video. Data yang diperoleh dianalisis dengan membandingkan hasil pengamatan selama proses pembelajaran dengan dugaan lintasan belajar (Hypothetical Learning Trajectory) dengan triangulasi data dan interpretasi silang.

\section{HASIL DAN PEMBAHASAN}

Proses teaching experiment dilaksanakan di kelas B SMK Baiturrahim dengan 28 siswa. Guru model pada tahap ini adalah guru mata pelajaran matematika di sekolah tersebut. Pada pelaksanaan, guru mengelompokkan siswa (kelompok 1-6). Pengelompokkan siswa didasarkan dari kemampuan homogen dan kemampuan heterogen 
siswa, yang mana pada setiap kelompok diisi oleh siswa yang mempunyai kemampuan berpikir rendah,sedang, dan tinggi. Peran peneliti pada teaching experiment adalah sebagai pengamat untuk mengetahui kreatifitas dan strategi siswa pada saat menyelesaikan masalah yang diberikan. Hypothetical Learning Trajectory yang digunakan peneliti pada teaching experiment merupakan revisi pada tahapan sebelumnya. pelaksanaan teaching experiment dapat diuraikan sebagai berikut.

Aktivitas pertama siswa diberikan masalah mengenai rute perjalanan. Siswa diminta untuk mengilustrasikan rute perjalanan mereka ke sekolah pada lembar aktifitas yang diberikan. Dari aktivitas tersebut peneliti berharap siswa lebih memahami bahwa ada dua hal penting dalam membuat rute perjalanan, yaitu yang pertama adalah tempat-tempat, lokasi-lokasi atau bangunan-bangunan yang dalam permasalahan ini nantinya dapat diubah menjadi titik-titik, dan yang kedua adalah bangunan satu menuju bangunan berikutnya atau titik satu menuju titik lainnya adalah ruas garis yang mana nantinya ruas garis tersebut dapat disebut juga dengan Vektor.
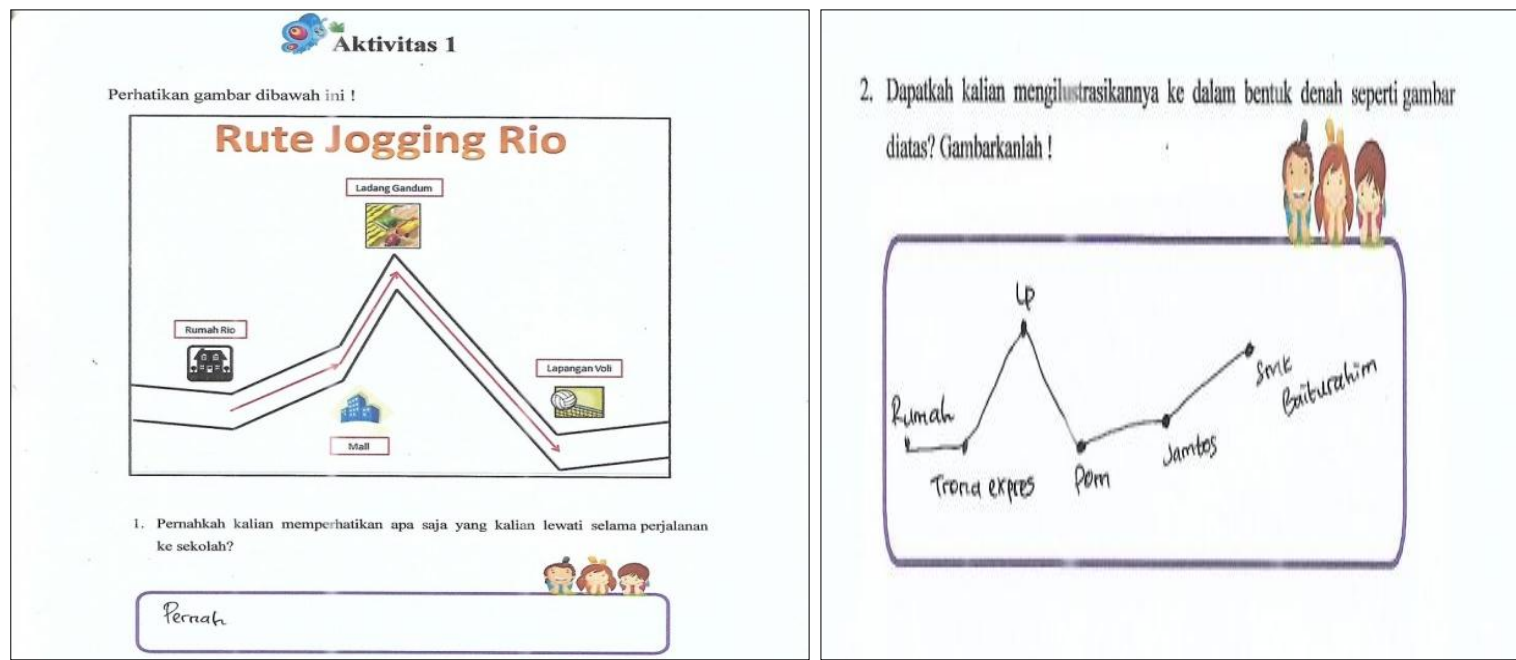

Gambar 2. Siswa Mengilustrasikan Rute Perjalanan dari Rumah ke Sekolah

Pada Gambar 2, siswa telah dapat mengilustrasikan rute perjalanan siswa ke sekolah kemudian menjawab pertanyaan yang tertera pada lembar aktivitas. Aktivitas pertama bertujuan membuat siswa memahami vektor dari konteks kehidupan sehari-hari yaitu mengenai rute perjalanan. Dari kegiatan ini dapat disimpulkan bahwa siswa dapat memahami salah satu contoh dari permasalahan yang berkaitan dengan vektor dalam kehiduapan sehari-hari adalah rute perjalanan dari satu tempat ke tempat yang lain. Berdasarkan Gambar 2 menunjukkan bahwa pada akhir aktivitas 1, siswa telah dapat mengetahui bahwa salah satu contoh dari vektor adalah dalam situasi mengenai rute 
perjalanan dari satu tempat ke tempat yang lain. Dari jawaban siswa juga dapat terlihat bahwa siswa memahami bangunan-bangunan atau lokasi-lokasi nantinya dapat di ilustrasikan menjadi titik-titik.

Selanjutnya pada aktivitas kedua, siswa diberikan permasalahan yang masih berkaitan dengan permasalahan mengenai rute perjalanan. Pada aktivitas ini siswa diberikan permasalahan mengenai rute perjalanan yang mana bangunan-bangunan atau lokasi-lokasi tertentu nantinya dapat dilambangkan dengan titik-titik dan kemudian titik satu dengan titik lainnya tersebut dapat dihubungkan menjadi vektor-vektor. Kemudian siswa juga diminta untuk menggambarkannya kedalam koordinat kartesius dan juga siswa diminta untuk menghitung penjumlahan dan pengurangan dari vektor-vektor yang mereka telah dapatkan dengan menggunakan rumus atau cara manual. Pada akhir aktivitas kedua, siswa diminta untuk menjelaskan apa itu vektor dengan menggunakan bahasa mereka sendiri. Setelah itu siswa juga diminta untuk menggunakan software geogebra dan kemudian membandingkan jawaban mereka dengan cara manual sebelumnya.
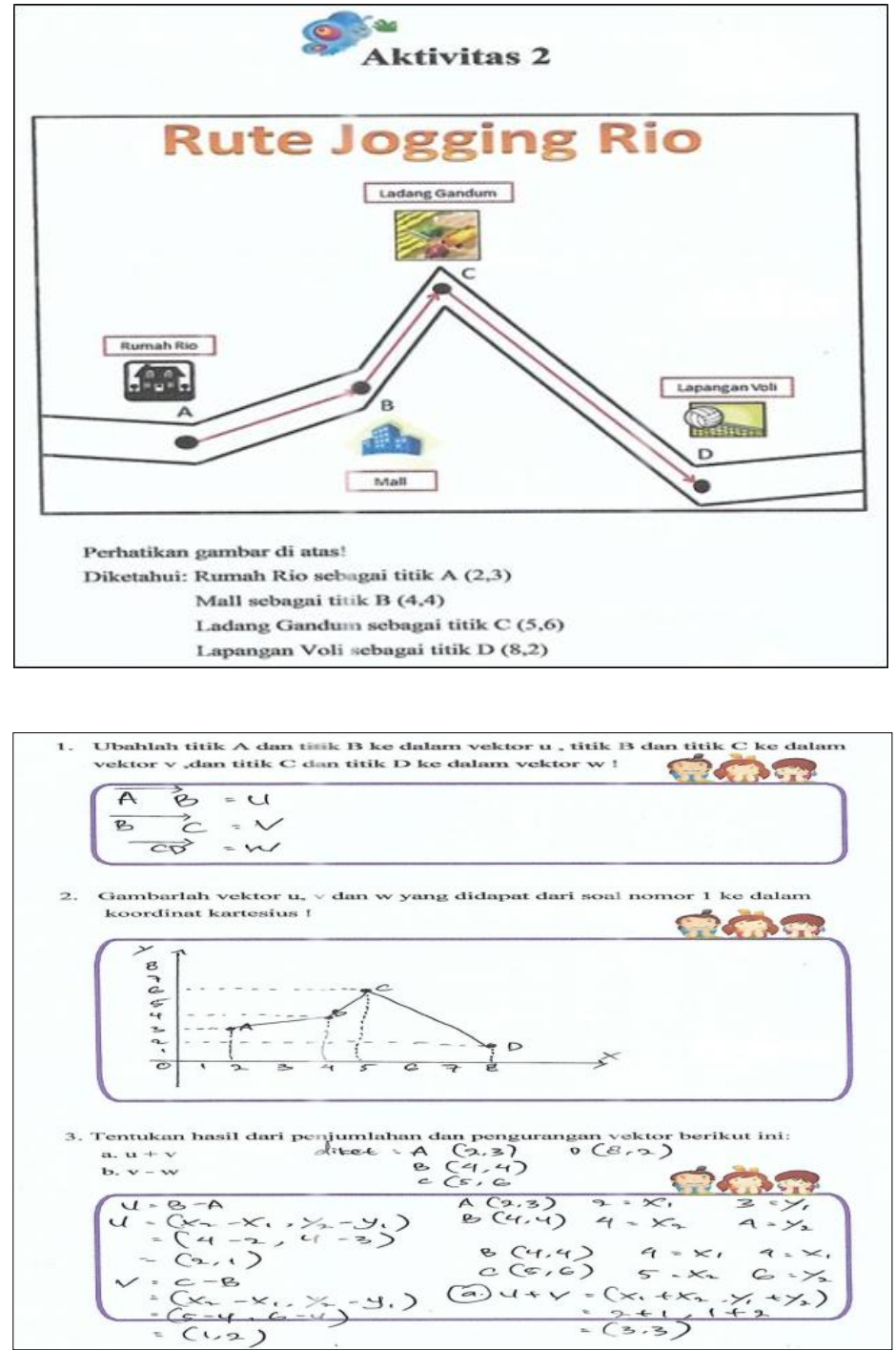
Gambar 3. Lembar Jawaban Siswa Aktivitas Kedua
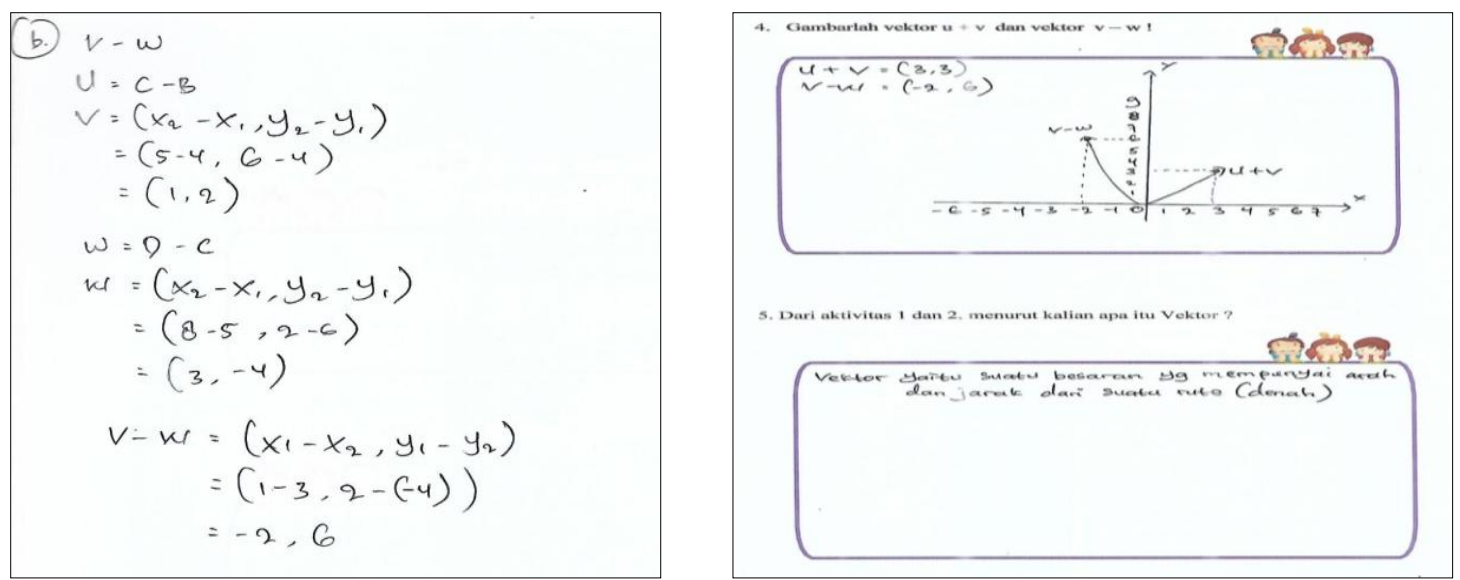

Gambar 4. Lanjutan Lembar Jawaban Siswa Aktivitas Kedua

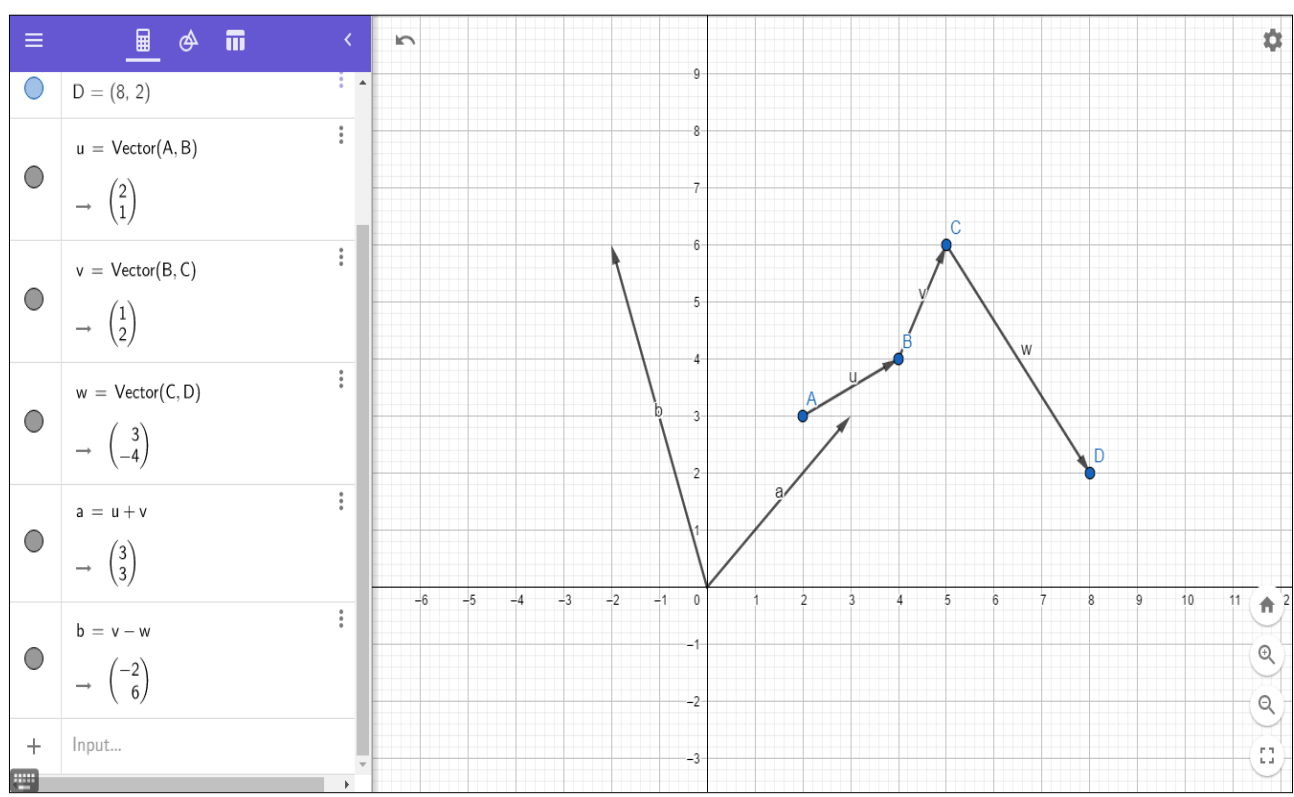

Gambar 5. Jawaban Siswa Aktivitas Kedua Menggunakan Software Geogebra

Aktivitas dua ini bertujuan untuk bagaimana siswa memahami cara mengubah titiktitik pada permasalahan ke dalam vektor dan menggambarkannya ke dalam koordinat kartesius. Kemudian siswa dapat memahami bagaimana menyelesaikan permasalahan yang berhubungan dengan operasi penjumlahan dan pengurangan vektor menggunakan software geogebra. Berdasarkan hasil jawaban siswa dapat disimpulkan bahwa siswa dapat memahami penjumlahan dan pengurangan vektor, dan siswa dapat memahami definisi vektor menggunakan bahasa mereka sendiri. Siswa juga telah dapat menyelesaikan permasalahan yang berhubungan dengan vektor yang diberikan khususnya dalam operasi penjumlahan dan pengurangan vektor. 
Selanjutnya pada aktivitas ketiga terdiri dari 2 persoalan yang harus diselesaikan oleh siswa. Persoalan pertama dan kedua yaitu masih mengenai penjumlahan dan pengurangan vektor akan tetapi dalam bentuk yang lebih rumit. Siswa juga diminta untuk menentukan penjumlahan dan pengurangan vektor dari aktivitas yang diberikan menggunakan geogebra. Siswa juga boleh menyelesaikan permasalahan pada aktivitas ketiga tersebut dengan mengunakan rumus atau cara manual dan membandingkannya dengan menyelesaikan permasalahan tersebut dengan menggunakan geogebra.

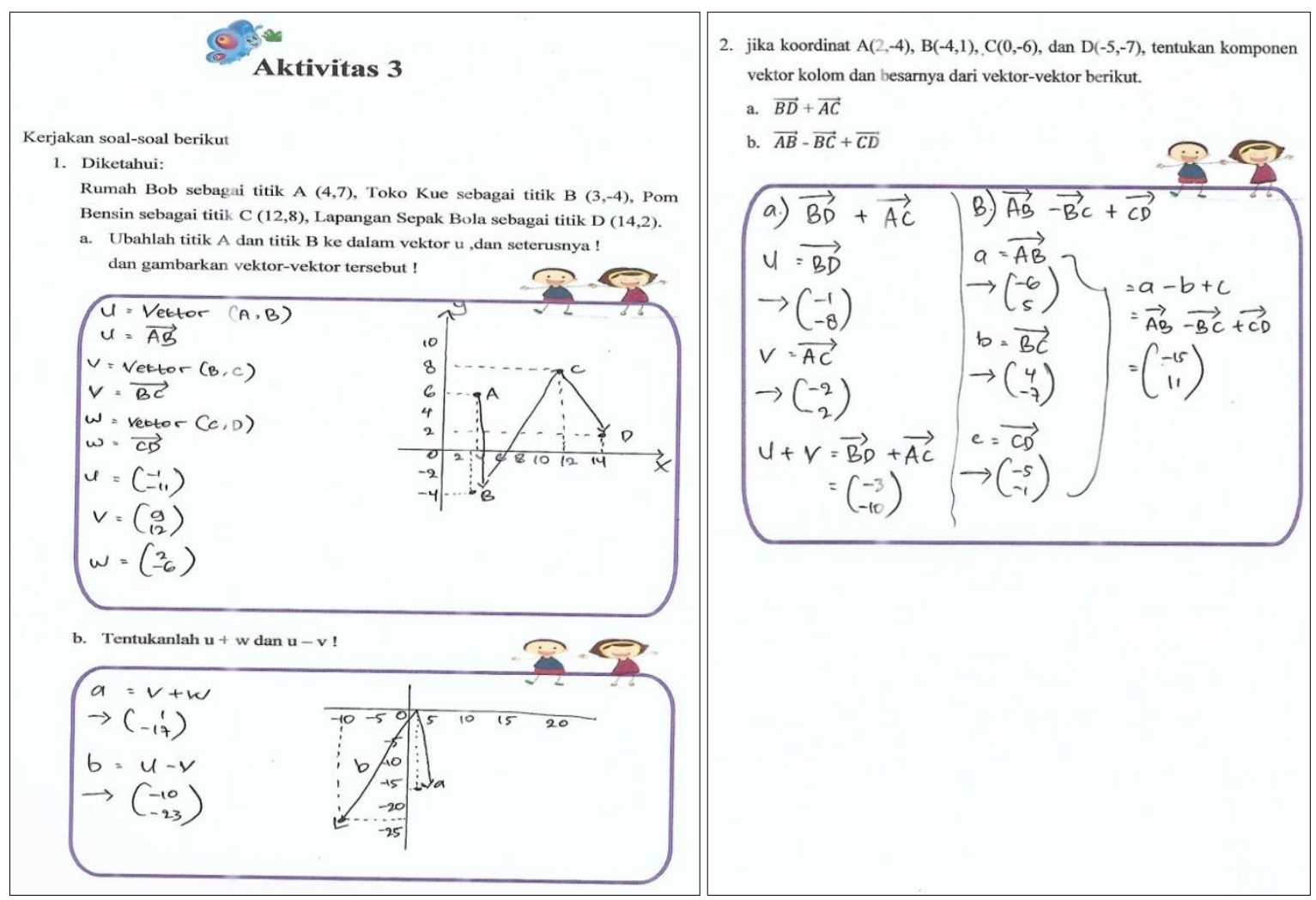

Gambar 6. Lembar Jawaban Siswa Aktivitas Ketiga
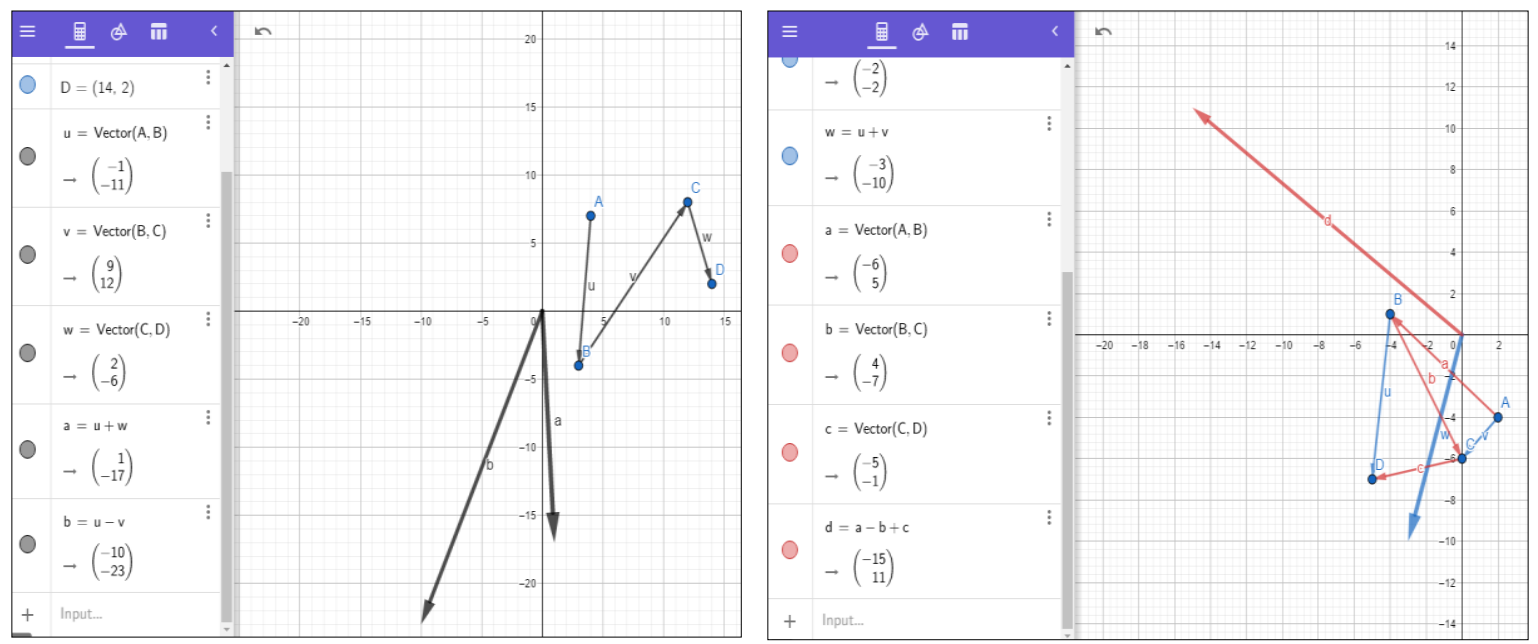

Gambar 7. Jawaban Siswa Aktivitas Ketiga Menggunakan Software Geogebra 
Aktivitas ketiga bertujuan untuk melihat pemahaman siswa dalam menyelesaikan permasalahan yang berhubungan dengan operasi (penjumlahan dan pengurangan) vektor. Untuk permasalahan pertama tentang mengubah titik-titik ke dalam vektor, kemudian menggambarkannya pada koordinat kartesius dan menghitung penjumlahan dan pengurangan pada permasalahan yang diberikan, pada lembar jawaban siswa dapat dilihat bahwa siswa telah dianggap mampu memahami cara menyelesaikannya yang mana siswa melakukannya dengan menggunakan geogebra. Pada permasalahan kedua dalam aktivitas ketiga ini tentang penjumlahan dan pengurangan vektor dalam bentuk yang lebih rumit, pada lembar jawaban siswa juga dapat dilihat bahwa siswa juga telah dapat menyelesaikan permasalahan tersebut juga dengan menggunakan geogebra. Hal ini membuktikan bahwa geogebra dapat memudahkan siswa dalam menyelesaikan permasalahan vektor khususnya pada operasi penjumlahan dan pengurangan.

Berdasarkan lintasan belajar yang telah dirancang dan diimplementasikan sebelumnya, terdapat tiga aktivitas pembelajaran pada tahap teaching experiment. Kegiatan penutup setiap pembelajaran yakni mempresentasikan hasil diskusi kelompok ke depan kelas. Selain itu, kelompok yang presentasi memiliki kesempatan mempertahankan pendapat mereka. Dan guru juga memberikan feedback atau umpan balik pembelajaran yang telah dipelajari siswa. Apakah siswa sudah memahami materi yang diberikan ataukah belum.

Setelah guru menutup kegiatan pembelajaran, guru memberikan lembar yang berisikan kesan dan pesan siswa setelah belajar materi vektor menggunakan software geogebra. Berdasarkan hasil analisis dari lembar kesan dan pesan terlihat bahwa siswa sangat terbantu dan merasa menggunakan geogebra dapat memudahkan mereka dalam menyelesaikan masalah yang berhubungan dengan vektor.
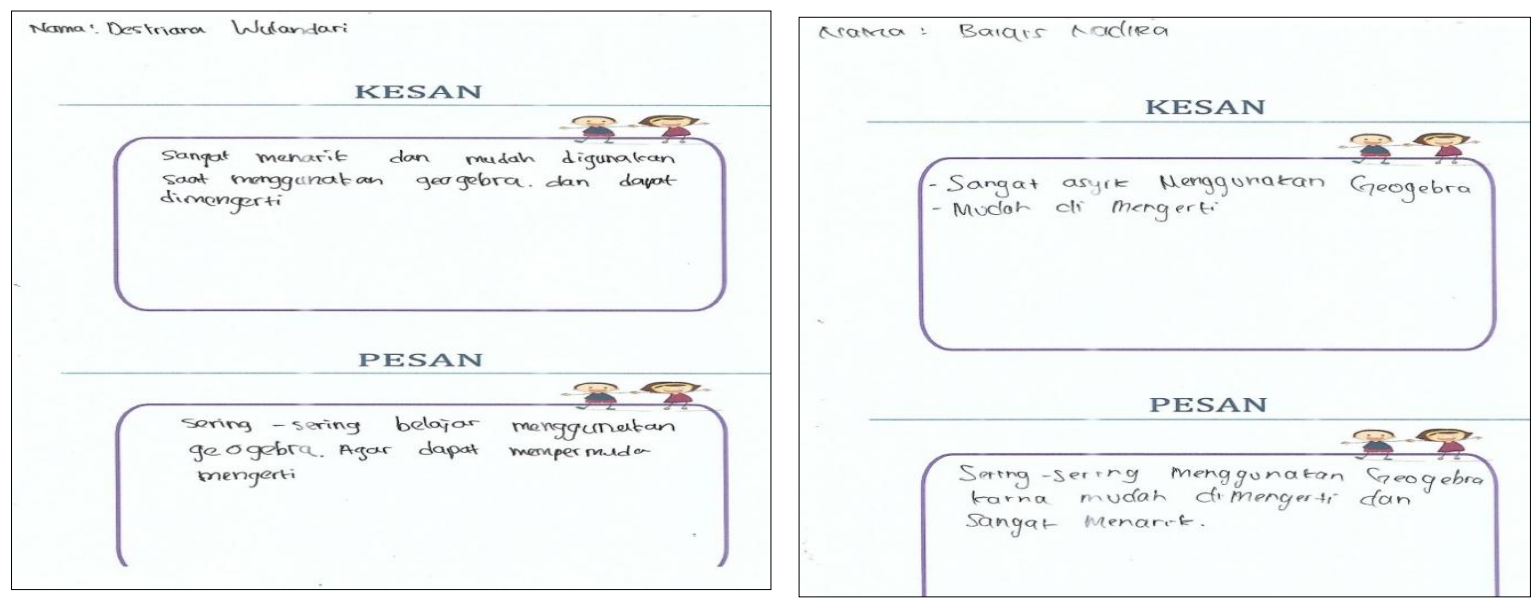

Gambar 8. Lembar kesan dan pesan 
Pada penelitian ini, geogebra berperan untuk membuat siswa lebih mudah dalam memahami konsep yang berhubungan dengan vektor karena setiap titik-titik yang di input akan langsung memunculkan gambar pada koordinat kartesius. Hal ini selaras dengan hasil penelitian Rahadyan, Purni dan Aulia (2018) bahwa aplikasi Geogebra dapat media pembelajaran virtual sehingga dapat menarik minat belajar siswa, serta dapat membantu siswa menjadi lebih mudah dalam melakukan operasi pada vektor khususnya pada operasi penjumlahan dan pengurangan sehingga siswa menjadi lebih mudah untuk menyelesaikan permasalahan yang berhubungan dengan penjumlahan dan pengurangan vektor terlihat dari jawaban siswa pada lembar aktivitas siswa. Penelitian terdahulu menyatakan pembelajaran menggunakan Geogebra dapat dimanfaatkan sebagai alat untuk menanamkan konsepkonsep matematis (Asngari, 2015), Penelitian Sylviani \& Fahmi (2019) Geogebra dapat digunakan di ruang kelas untuk mengeksplorasi beberapa konsep dasar dalam matematika, khususnya geometri. Hal tersebut menunjukkan bahwa Geogebra memiliki banyak kemungkinan untuk digunakan sebagai alat untuk membantu siswa dalam mendapatkan perasaan intuitif dan memvisualisasikan proses matematika yang memadai. Sedangkan menurut Suweken (2013) yang menemukan bahwa media pembelajaran virtual berbasis GeoGebra pada proses pembelajaran matematika dapat meningkatkan pemahaman konsep matematika siswa

\section{KESIMPULAN}

Berdasarkan dari hasil penelitian dan pembahasan, dapat disimpulkan bahwa lintasan pembelajaran yang diperoleh terdiri dari 3 aktivitas. Yakni aktivitas 1, Siswa mengilustrasikan rute perjalanan dan menjelaskan cara menentukan jarak dari satu tempat ketempat yang lain. Aktivitas 2, Siswa mengubah dua titik yang berhubungan menjadi vektor dan menggambarkannya kedalam koordinat kartesius, memahami definisi vektor menggunakan bahasa mereka sendiri dan memahami penjumlahan dan pengurangan vektor menggunakan geogebra. Aktivitas 3, Siswa menyelesaikan permasalahan yang berhubungan dengan penjumlahan dan pengurangan vektor dalam bentuk yang lebih rumit Selain itu, hasilnya menunjukkan bahwa penggunaan geogebra dapat membantu siswa dalam memahami konsep dan menyelesaikan permasalahan yang berhubungan dengan vektor khususnya penjumlahan dan pengurangan vektor. Serta dapat dijadikan sebagai salah satu sumber media pembelajaran matematika pada pembelajaran lainnya yang dapat meningkatkan motivasi dan kemampuan berpikir kritis siswa. 


\section{REFERENSI}

Asngari, D. R. (2015). Penggunaan Geogebra dalam Pembelajaran Geometri. Seminar Nasional Matematika Dan Pendidikan Matematika UNY, 299-302.

Budiman, H., \& Rosmiati, M. (2020). Penerapan Teori Belajar Van Hiele Berbantuan Geogebra untuk Meningkatkan Kemampuan Penalaran Matematis Siswa. Prisma, 9(1), 47. https://doi.org/10.35194/jp.v9i1.845

Gravemeijer, K. (2004). Local Instruction Theories as Means of Support for Teachers in Reform Mathematics Education. Mathematical Thinking and Learning, 6(2).

Gravemeijer, K., \& Eerde, D. V. (2009). Design Research As A Meants For Building A Knowledge Base For Teaching In Mathematics Education. The Elementary School Journal, 109(5), 510-524.

Japa, N., Suarjana, \& Widiana. (2017). Media Geogebra dalam Pembelajaran Matematika. Journal of Natural Science and Engineering, 1(2), 40-47.

Kurniawati, N. (2018). Pengembangan Media Pembelajaran Lembar Kerja Peserta Didik (LKPD) Berbantuan Geogebra Pada Materi Turunan. Skripsi: UIN Raden Intan Lampung.

Maskur, R., Sumarno, Rahmawati, Y., Pradana, K., Syazali, M., Septian, A., \& Palupi, E. K. (2020). The effectiveness of problem based learning and aptitude treatment interaction in improving mathematical creative thinking skills on curriculum 2013. European Journal of Educational Research, 9(1), 375-383. https://doi.org/10.12973/eu-jer.9.1.375

Murizal, A., Yarman, \& Yerizon. (2012). Pemahaman Konsep Matematis dan Model Pembelajaran Quantum Teaching. Jurnal Pendidikan Matematika, 1(1), 19-23.

Putra, R. W. Y., \& Anggraini, R. (2016). Pengembangan Bahan Ajar Materi Trigonometri Berbantuan Software Imindmap Pada Siswa Di SMA. Jurnal Al-Jabar, 7(1), 39-47.

Septian, A, Darhim, \& Prabawanto, S. (2020). Geogebra in integral areas to improve mathematical representation ability. Journal of Physics: Conference Series, 1613, 012035. https://doi.org/10.1088/1742-6596/1613/1/012035

Septian, Ari. (2017). Penerapan Geogebra untuk Meningkatkan Kemampuan Pemecahan Masalah Matematis Mahasiswa Program Studi Pendidikan Matematika Universitas Suryakancana. PRISMA, 6(2). https://doi.org/10.35194/jp.v6i2.212

Septian, Ari, Sugiarni, R., \& Monariska, E. (2020). The Application of Android-based GeoGebra on Quadratic Equations Material toward Mathematical Creative Thinking ability. Al-Jabar: Jurnal Pendidikan Matematika. https://doi.org/10.24042/ajpm.v11i2.6686

Suherman, E. dkk. (2011). Strategi Pembelajaran Matematika Kontemporer. Bandung: PT Remaja Rosdakarya, 133, 31-59. https://doi.org/10.1016/j.proeng.2015.12.621

Suryawan, I. P. P., \& Permana, D. (2020). Media Pembelajaran Online Berbasis Geogebra sebagai Upaya Meningkatkan Pemahaman Konsep Matematika. Prisma, 9(1), 108. https://doi.org/10.35194/jp.v9i1.929

Suwarto, \& Purnami, A. S. (2018). Upaya Meningkatkan Pemahaman Konsep Matematika Melalui Hypothenical Learning Trajectory Pada Materi Vektor. Jurnal Indomath, 1(2), 69-76.

Wijayanti, S., \& Sungkono, J. (2017). Pengembangan Perangkat Pembelajaran mengacu Model Creative Problem Solving berbasis Somatic, Auditory, Visualization, Intellectually. Al-Jabar: Jurnal Pendidikan Matematika, 8(2), 101. https://doi.org/10.24042/ajpm.v8i2.1941 